\title{
MARGINAL ACCURACY OF HYBRID AND DIFFERENT MACHINABLE CERAMIC CROWNS
}

\author{
Walaa Ossama El Mekkawi*
}

\begin{abstract}
Purpose: The aim of the present study was to evaluate marginal accuracy of hybrid and different ceramic crowns.

Material and Methods: Forty sound human maxillary central incisors were selected and received standardized preparation with shoulder finish line. They were divided into four groups according to the material of construction: Group I: VITA Enamic , Group II: E.max CAD, Group III Celtra-Duo, Group IV: VIA Suprinity ( $\mathrm{n}=10)$. The crowns were fabricated from blocks using CAD/ CAM system. All crowns were cemented using self adhesive resin cement. Marginal discrepancy (pre and post cementation) was tested for all samples. Data were tabulated and statistically analyzed. The results were collected, arranged and tabulated to be statistically analyzed.
\end{abstract}

Results: The highest mean value of marginal gap was found in E-max cad group, followed by Celtra-Duo group, followed by VITA Suprinity group while the lowest mean value was found in VITA Enamic group. The samples of VITA Enamic showed the lower marginal gap values compared to the other samples either before $(29.5 \mu \mathrm{m} \pm 1.5)$ or after cementation $20.97 \mu \mathrm{m} \pm 1.45)$. The samples of E-max cad showed the highest marginal gap values compared to the other samples either before $(33.8 \mu \mathrm{m} \pm 0.75)$ or after cementation $(30.6 \mu \mathrm{m} \pm .0 .6)$.

Conclusion: Hybrid ceramics crowns introduced the highest marginal accuracy while E-max cad crowns introduced the lowest marginal accuracy. Zirconia reinforced Lithium silicate restorations, particularly the partially crystalline form, introduced better marginal accuracy than Hybrid ceramics restorations.

KEY WORDS: VITA Enamic, E-max, VITA Suprinity, reinforced ceramics, Marginal accuracy.

\section{INTRODUCTION}

Dental crowns have been used for decades to restore compromised or heavily restored dentition, and for esthetic improvements. New CAD/CAM materials and systems have been developed in the last decade for fabrication of all ceramic restorations. Several systems for esthetic restorations have been developed in response to increasing demands from both patients and dentists ${ }^{(1-4)}$.

\footnotetext{
* Crown \& Bridge Department Faculty of Dentistry Al Azhar University
} 
Chair side Computer Aided Design/ Computer Aided Manufacturing (CAD/CAM) is recently gaining rapid popularity because it allows the dentist to eliminate the need for certain laboratory steps, and to obtain a constant quality of work. Ceramic material has been advocated rather than metal ceramic restorations because of their excellent esthetic and acceptable mechanical properties. Although metal ceramic crowns have superior durability, there are some undesirable characteristics, such as the need of the opaque porcelain to mask the metallic substructure ${ }^{(5)}$. Esthetically pleasing pressable all-ceramic crowns exhibit low resilience and toughness and are, therefore, susceptible to fracture $^{(6)}$ and their higher wear resistance can damage opposing teeth ${ }^{(7)}$.

Most ceramic materials exhibit low resilience and are more susceptible to fracture; Hybrid Enamic is a recently introduced ceramic network material that has higher resilience, lower wear resistance (less damage to opposing teeth), and allow for easy repair $^{(6)}$.

Glass ceramics may be ideally suited for use as dental restorative materials. Their mechanical and physical properties have generally improved, including increased fracture resistance, improved thermal shock resistance, and resistance to erosion $^{(8)}$. The glass matrix is infiltrated by micronsize crystals of leucite or lithium disilicate, creating a highly filled glass matrix ${ }^{(9)}$.

Ceramics reinforced by lithium disilicate (eg, IPS e.max) are true glass ceramics, with the crystal content increased to approximately $70 \%$ and the crystal size refined to improve flexural strength. The material is translucent enough that it can be used for full-contour restorations or for the highest aesthetics and can be veneered with special porcelain. Because of the favorable translucency and variety of shades possible, the material can be used for fully anatomic (monolithic) restorations with subsequent staining characterization or as a core material with subsequent coating with veneering ceramics ${ }^{(10)}$.
New additions are zirconia-reinforced lithium silicates (ZLSs) (eg, Vita Suprinity, Celtra Duo ). ZLS materials comprise a lithium-silicate glass ceramic that is strengthened with approximately $10 \%$ zirconia crystals. Vita Suprinity, introduced in a partially crystalline form and exhibits its final esthetic and physical properties only after final crystallization in a specialized dental furnace (Vita), unlike Celtra duo which introduced in a fully crystalline stage with no need to the crystallization $\operatorname{step}^{(11)}$.

Inaccurate margin create spaces between the margin of restoration and the prepared tooth surface. Disturbance in the marginal accuracy can create stress concentrations that reduce the strength of the restoration and causes its fracture ${ }^{(12)}$. Some authors said that the margin of the restoration is considered clinically accepted when the marginal gaps and cement thicknesses is $<120 \mu \mathrm{m}$. Different methods and testing techniques have been used to evaluate the marginal adaptation including direct microscope, cross sectional views, light bodied impression replica, laser videography using light bodied impression replica, profilometry and $\mathrm{X}$ ray micro-tomography which viewed $2 \mathrm{D}$ and $3 \mathrm{D}$ imaging of the space between the tooth/model die and restoration ${ }^{(13)}$.

This study was performed to evaluate the marginal accuracy, of Hybrid, Lithium Disilicat, Celtra duo and Vita Suprinity ceramic crowns

\section{MATERIAL AND METHODS}

This study included forty sound human maxillary central incisors were selected to conduct this in vitro study.

\section{Samples selection}

A total of forty caries-free human maxillary central incisors were selected for this study. The teeth were examined for being approximately equal in the mesio-distal and inciso-cervical dimentions at the coronal portion. The crowns were scaled, cleaned with rotating brushes and pumice. They were then 
stored in saline solution at room temperature $37^{\circ} \mathrm{C}$. Ethical approval for the use of extracted human teeth was obtained in accordance with guidelines from research ethics committee of Faculty of dental medicine (Girls'Branch), Al Azhar University.

Ethical approval for the use of extracted human teeth will be obtained in accordance with guidelines from research ethics committee of Faculty of dental medicine (Girls' Branch), Al Azhar University.

\section{Tooth preparation:}

- Forty sound human maxillary central incisors were selected and received standardized preparation with shoulder finish line. A specially cylindrical shaped split copper rings were used for construction of the epoxy blocks and the inner surface of the rings were painted with separating medium, Fig.(1).

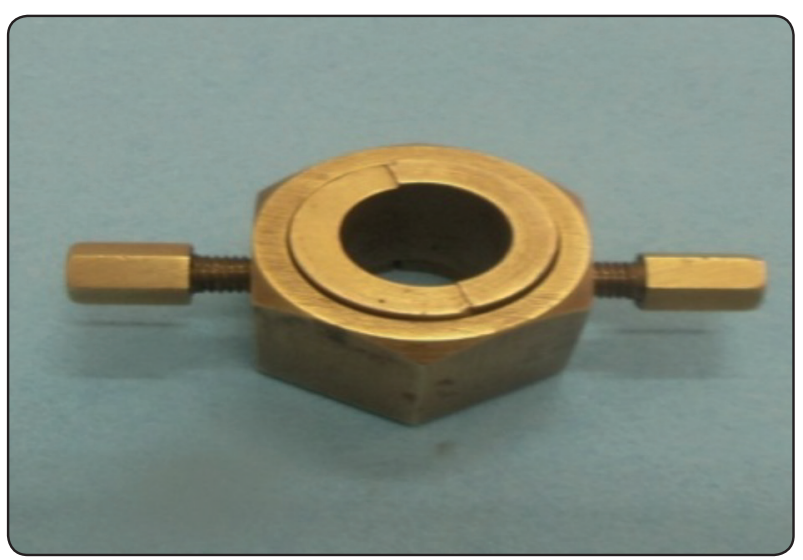

Fig (1): Copper ring
- The recommended proportions of the polymer and the monomer of the epoxy resin was mixed according to the manufacturer's instructions and poured immediately into the copper cylinder then the abutment tooth was fixed vertically in the center of the epoxy resin.

- After complete setting of the epoxy resin, the copper rings removed.

- All selected teeth received a standardized preparation with shoulder finish line $1.2 \mathrm{~mm}$ using centroid cnc machine.

- They were divided into four groups according to the material of construction: Group I: 10 teeth for Vita Enamic crowns, Group II: 10 teeth for E.max CAD crowns, Group III:10 teeth for Celtra Duo crowns, Group IV:10 teeth for V Suprinity crowns.

\section{Crowns fabrication:}

- All prepared teeth were scanned by using inlab software version 3.8. A CAD/CAM milling machine had been used to mill the ceramic blocks. Using a CAD/CAM system for the crowns fabrication by milling vita enamic blocks, E.max cad blocks ,Celtra Duo blocks and Vita Suprinity blocks to get 4 groups of crowns: Group I: 10 Hybrid crowns, Group II: 10 E.max crowns, Group III: 10 Celtra Duo crowns, Group IV: 10 Vita Suprinity crowns.

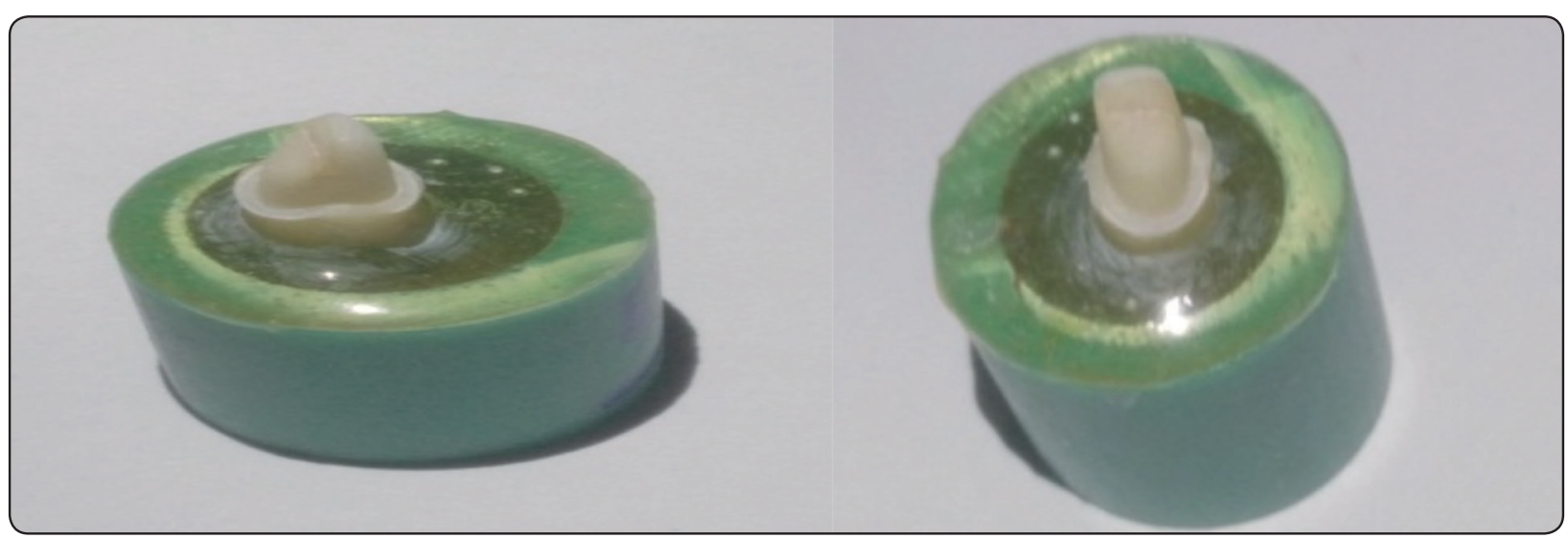

Fig (2):Tooth preparation with shoulder finish line 
TABLE (1): Materials composition and manufacture used in this study:

\begin{tabular}{|c|c|c|c|}
\hline Materials & $\begin{array}{l}\text { Commercial } \\
\text { names }\end{array}$ & Main composition & Manufacturer \\
\hline $\begin{array}{l}\text { Hybrid ceramic } \\
\text { blocks }\end{array}$ & VITA ENAMIC & $\begin{array}{l}\text { Ceramic part }\left(86 \mathrm{wt} \% / 75 \mathrm{vol} \% \text { ): silicone dioxide } \mathrm{SiO}_{2} \text {, }\right. \\
\text { Aluminum oxide } \mathrm{Al}_{2} \mathrm{O}_{3} \text {, Sodium oxide } \mathrm{Na}_{2} \mathrm{O} \text {, Potassium Oxide } \\
\mathrm{K}_{2} \mathrm{O} \text {, Boron trioxide } \mathrm{B}_{2} \mathrm{O}_{3} \text {, Zirconia } \mathrm{ZrO}_{2} \text {, Calcium oxide } \mathrm{KaO} \text {. } \\
\text { Polymer part ( } 14 \mathrm{wt} \% \text { / 25vol\%): UDMA (urethane } \\
\text { dimethacrylate), TEGDMA (trithylene glycol dimethacrylate) }\end{array}$ & $\begin{array}{l}\text { Vita, Zahnfabrik, } \\
\text { Germany. }\end{array}$ \\
\hline $\begin{array}{l}\text { Lithium } \\
\text { disilicate } \\
\text { ceramic blocks }\end{array}$ & E.Max & $\begin{array}{l}\text { Lithium disilicate glass ceramic, } \mathrm{SiO}_{2} \\
\text { Additional contentes: } \mathrm{Li}_{2} \mathrm{O}, \mathrm{K}_{2} \mathrm{O}, \mathrm{MgO}, \mathrm{Al}_{2} \mathrm{O}_{3}, \mathrm{P}_{2} \mathrm{O}_{5} \text { and other } \\
\text { oxides }\end{array}$ & $\begin{array}{l}\text { Ivoclar Vivadent, } \\
\text { Liechtenstein } \\
\text { Germany }\end{array}$ \\
\hline $\begin{array}{l}\text { Celtra-Duo } \\
\text { (Fig. 3) }\end{array}$ & $\begin{array}{l}\text { Zirconia } \\
\text { reinforced } \\
\text { lithium silicate }\end{array}$ & $\begin{array}{l}\text { (ZLS) is mainly composed of } 58 \% \text { silica, lithium-metasilicate, } \\
\text {-disilicate, and -phosphate crystals, and } 10 \% \text { zirconia crystals in } \\
\text { addition to other minor ingredients }\end{array}$ & $\begin{array}{l}\text { Dentsply, } \\
\text { Germany. }\end{array}$ \\
\hline $\begin{array}{l}\text { Vita suprnity } \\
\text { (Fig. 2) }\end{array}$ & $\begin{array}{l}\text { Zirconia } \\
\text { reinforced } \\
\text { lithium silicate }\end{array}$ & $\begin{array}{l}-\mathrm{ZrO} 2 \text { (zirconium dioxide) } 8-12 \% \\
-\quad \mathrm{SiO} 2 \text { (silicone dioxide) } 56-64 \% \\
-\quad \mathrm{LiO} 2 \text { (lithium oxide) } 15-21 \% \\
\text { Various } 10 \%>\end{array}$ & $\begin{array}{l}\text { Vita-zahnfabrik, } \\
\text { Germany. }\end{array}$ \\
\hline $\begin{array}{l}\text { Self-adhesive } \\
\text { resin cement }\end{array}$ & $\begin{array}{l}\text { Rely X unicem } \\
\text { (Aplicap) }\end{array}$ & $\begin{array}{l}\text { Powder: Alkaline (basic) fillers, Silanated fillers, Initiator } \\
\text { components, Pigments. } \\
\text { Liquid: Methacrylate monomers containing phosphoric acid } \\
\text { groups, Initiator components, Stabilizers. }\end{array}$ & $\begin{array}{l}\text { 3M ESPE, } \\
\text { Seefeld, Germany. }\end{array}$ \\
\hline Epoxy resin & Kemapoxy 150 & $\begin{array}{l}\text { Two components, solvent free, non-pigmented liquid epoxy } \\
\text { resin. }\end{array}$ & $\begin{array}{l}\text { CMB } \\
\text { International, } \\
\text { Giza, Egypt. }\end{array}$ \\
\hline
\end{tabular}

\section{A) Scanning of the preparations.}

- All the prepared teeth were coated by spraying them with a light reflecting anti-glare spray "Cerec optispray" * and then fixed using plasticine on the shifting plate of the in-Lab scanner "inEos"". The shifting plate with the sample fixed on it was then positioned on the $\mathrm{XY}$ table of the inEos for taking the optical impression after adjusting the height of the scanner vertical unit with the rotary knob until the preparation was sharply focused. A $45^{\circ}$ view scan was done of the preparation surface by clicking on the "acquire image", then the in-lab software uses those images for transforming them into a $3 \mathrm{D}$ virtual models.

\section{B) Designing of the restoration.}

- On the computer screen a 3D model was created, the margins were identified and the path of insertion was determined to prepare the restoration for editing.

\section{C) Milling of the crowns}

- After the restorations had been designed, the milling preview window was activated to start the milling process. The dialog box allows

* Sirona Dental Systems GmbH, 64625 Bensheim, Germany

* Sirona Dental Systems GmbH, D-64625 Bensheim, Germany.

* Komit, GEBR, BRASSELER, Lemgo, Germany. 
for choosing the type and size of the material according to the type of the restoration to be milled.

- The in-lab MC XL* milling machine was then activated and the block) was manually scanned with a laser scanner attached to the milling machine in order to be able to calculate the block size and percentage of magnification before starting the milling procedures to compensate sintering shrinkage, then the block was fixed in the spindle of the milling machine and the door was closed then the milling icon was clicked to start the milling process.

\section{i) Hybrid (Vita enamic) ceramic crowns fabrication}

- Hybrid ceramic crowns were constructed using VITA ENAMIC blocks.

- The block was inserted and fixed into milling machine. The restorations were separated from the block at the end of milling and checked on the prepared teeth to be ready for testing. Inspection was also done for every crown on the corresponding tooth for proper seating.

- Before polishing of the milled restorations, they were cleaned by ultrasonic cleaner. The milled restorations were polished with vita Enamic polishing set technical using a micro motor. First the pink polishers of the vita enamic polishing set were used under water coolant, followed by high gloss polishing with the grey diamond coated polishers which was carried out without any water coolant. The polished samples were cleaned with alcoholic swap followed by ultrasonic cleaner.

\section{ii) IPS Emax Cad ceramic crowns fabrication:}

- Were constructed using E.max cad blocks.
- The block was inserted into the milling machine. The material comes prepared in a 'blue state', where it is composed primarily of lithium metasilicate.

- Once milling has been completed the restoration is subjected to a second round of heat treating. The manufacturer considers the material fully crystallized after being tempered at 850 degree C for 20-25 min under vaccum.

\section{iii) Celtra Duo ceramic crowns fabrication:}

- Celtra Duo block was inserted into the milling machine. a low speed diamond bur** was used to separate the completely milled restorations and to remove excess material at the site of connection with the ceramic block.

\section{iv) Vita Suprinity ceramic crowns fabrication}

- Vita Suprinity block was inserted into the milling machine.

\section{Cementation:}

- Self-adhesive Rely X Unicem resin cement was used for crowns cementation. Activation, mixing, placement, and final curing were done following the manufacturer recommendations. For activation the handle was pressed down completely and held for 2-4 seconds, then mixed for 10 seconds by using an amalgamator. After removing the capsule from the amalgamator, the capsule were inserted into an applier. The nozzle was opened and the cement was dispensed directly onto the fitting surface of each crown.

- Excess cement was removed after initial light curing for 2 seconds while the cement was in the gel state using a sharp explorer, then final curing was done for each surface for 20 seconds using light cure.

\footnotetext{
* Sirona Dental Systems GmbH, D-64625 Bensheim, Germany.

* Komit, GEBR, BRASSELER, Lemgo, Germany.
} 


\section{Marginal accuracy measurements}

- The marginal accuracy was measured for each specimen before and after cementation. A special designed holding device was used to apply a uniform static load on the tested crowns to ensure the accuracy of seating of the crowns to hold them in place during the examination process using stereomicroscope.

- Digital images of the margins were captured at eight predetermined measuring locations on both the coping and epoxy resin blocks using an incredible pen for each sample For each crown, the predetermined points corresponding to previously established guiding vertical lines were captured by CCD digital camera mounted on stereomicroscope. The microscopic field included in analysis was representative for the area related to the gap at the abutment crown interface, which is the vertical gap distance starting from the finish line to the edge of the external surface of the crown. Different readings for each crown at the area of abutment/ crown interface were calculated using the image analysis software program.

\section{RESULTS}

Statistical analysis was performed with IBM ${ }^{\circledR}$ SPSS ${ }^{\circledR}$ Statistics Version 25 for Windows. The mean and standard deviation values were calculated for each group. Normality test was performed using Shapiro-Wilk test and revealed normal distribution between values of each group. Homogeneity test was performed using Levene's test and revealed homogenous distribution between all variables. Therefore, 2 independent samples $\mathrm{T}$ test was performed between the samples of the same material before and after cementation, and one-way ANOVA test was performed between the different materials both before and after cementation (significance level was set at $\mathrm{P} \leq 0.05$ ) to reveal the statistical significant difference.

The results of the marginal gap were represented as means and standard deviation. The highest marginal gap value was recorded for E-max samples before cementation $(33.8 \mu \mathrm{m} \pm 0.75)$ followed by samples of Celtra samples $(33.77 \mu \mathrm{m} \pm 1)$. The lowest marginal gap value was recorded at VITA Enamic samples after cementation $(20.97 \mu \mathrm{m} \pm 1.45)$ preceded by Suprinity samples after cementation $(22.77 \mu \mathrm{m} \pm 2)$.

For all sample groups; the values of marginal gap before cementation were higher than the marginal gap values after cementation with a statistical significant difference.

The samples of VITA Enamic showed the lower marginal gap values compared to the other samples either before $(29.5 \mu \mathrm{m} \pm 1.5)$ or after cementation $20.97 \mu \mathrm{m} \pm 1.45)$.

The samples of E-max cad showed the highest marginal gap values compared to the other samples either before $(33.8 \mu \mathrm{m} \pm 0.75)$ or after cementation $(30.6 \mu \mathrm{m} \pm .0 .6)$.

TABLE (2): The mean, standard deviation (SD) of vertical marginal gap in different materials groups before and after cementation.

\begin{tabular}{|c|c|c|c|}
\hline Value & Before & After & P Value \\
\hline & Mean $(\mathrm{SD}) \mu \mathrm{m}$ & Mean (SD) $\mu \mathrm{m}$ & \\
\hline Emax & $33.80(0.75) \mathrm{b} \mathrm{A}$ & $30.60(0.60) \mathrm{b} B$ & $0.005 *$ \\
\hline Celtra & 33.77 (1.00) ab A & $29.20(1.20) \mathrm{b} \mathrm{B}$ & $0.007 *$ \\
\hline Suprinity & $30.43(2.00) \mathrm{a} \mathrm{A}$ & $22.77(2.00)$ a B & $0.009 *$ \\
\hline Enamic & $29.50(1.50)$ a A & 20.97 (1.45) a B & $0.002 *$ \\
\hline P Value & $0.1 *$ & $0.000 *$ & \\
\hline
\end{tabular}

* Indicates the mean difference is statistically significant at the 0.05 level.

Different small litter indicates statistically significant difference in the same column. (p-value $\leq 0.05$ ).

Different Capital litter indicates statistically significant difference in the same raw. (p-value $\leq 0.05)$. 


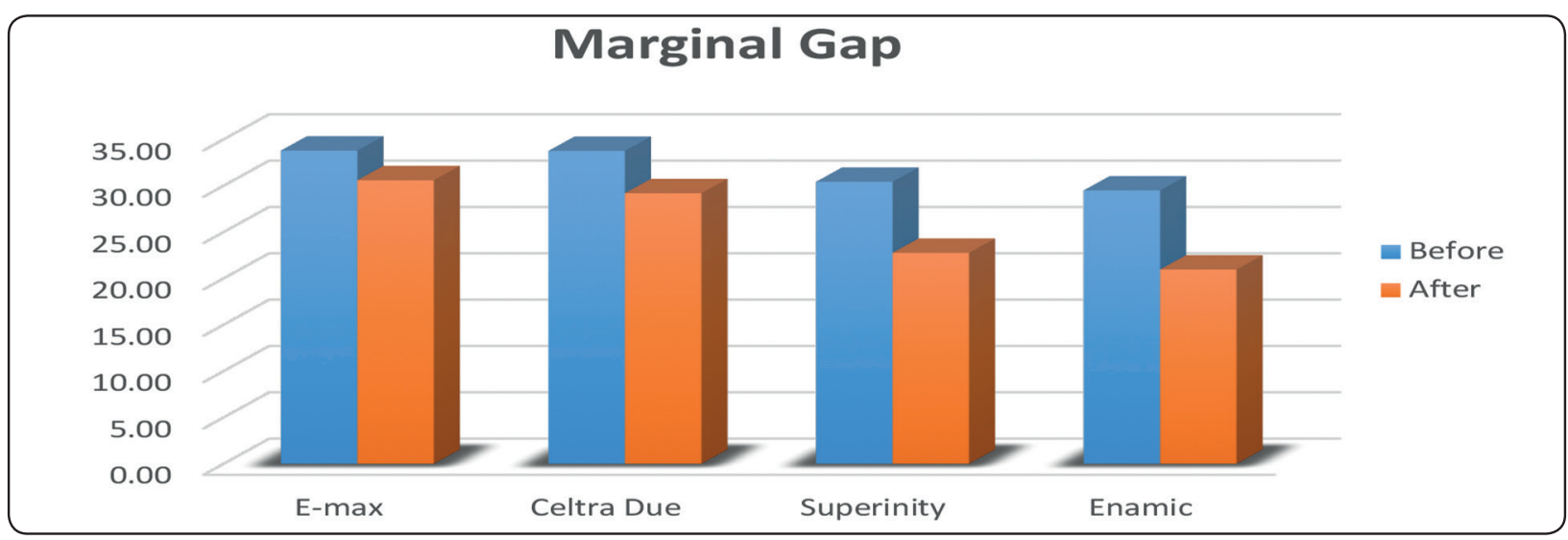

Fig (3):Marginal gap before \& after cementation

\section{DISCUSSION}

For marginal gap consideration, Irrespective of the material, it was found that the vertical gap distance after cementation is significantly lower than before cementation. That was not in agreement with a study that has reported an increase in the marginal discrepancy following luting with resin cements ${ }^{(14)}$. Another study also evaluated in vitro marginal fit of three all-ceramic crown systems before and after cementation and observed that both resin-modified glass ionomer and resin cements have induced increase in marginal discrepancy ${ }^{(15)}$. This decrease in the marginal gap after cementation in the current study may be attributed to the cement space that was created during crown designing allowing the cement to flow without affecting the marginal adaptation of the crown, in addition of using low viscosity self-adhesive Rely X Unicem cement. Resin cements with high viscosity may result in limited penetration time and consequently in a thick cement layer if insufficient pressure has been applied ${ }^{(16)}$.

Regardless of cementation, it was found that the highest statistically significant marginal gap values were recorded with E-max followed by Celtra duo, followed by VITA Suprinity, while the lowest statistically significant marginal gap distance values were for VITA Enamic. This was in agreement with some studies which proved that the E.max CAD specimens recorded higher vertical marginal gap mean values than that obtained with VITA Enamic specimens ${ }^{(17)}$. This may be attributed to geometrical design of the restoration and difficulties regarding scanning, digitization, and the milling process of brittle ceramic material. Moreover, the adaptation of restorations made out of milled ceramic blocks may be affected by the size of milling burs, and material conditions during the milling procedure ${ }^{(18-20)}$. Some authors proved that the restorative material type affects the performance of a CAD-CAM system relative to marginal adaptation ${ }^{(21)}$.

However, the results were not in accordance with Manhal and Samar who found that there is no statistically significant difference when compared the fitness of crowns made from $\mathrm{E}$ max CAD and the Vita Suprinity. Relating this result to the relative similarity in the chemical composition of both materials and similarity in post milling crystallization firing which was done in the same furnace at the same temperature for the same time. Thus they were exposed to same fabrication method from milling to firing process $^{(22)}$.

\section{CONCLUSIONS}

Under the test conditions, the following could be concluded:

1. Hybrid ceramics crowns introduced the highest marginal accuracy while E-max cad crowns introduced the lowest marginal accuracy. 
2. Zirconia reinforced Lithium silicate restorations, particularly the partially crystalline form, introduced better marginal accuracy than Lithium disilicate restorations.

\section{REFERENCES}

1. Zarone F, Ferrari M, Mango FG, Leone R, Sorrentino R: "Digitally Oriented Materials", International Journal of Dentistry. 2016;98:40-594.

2. McLean JW: Evolution of dental ceramics in the twentieth century. J prosthet Dent 2001;85:61-6.

3. Bindl A, Mormann WH: Survival rate of mono-ceramic and ceramic-core CAD/CAM-generated anterior crowns over 2-5 years. Eur J Oral Sci 2004;112:197-204.

4. Segal BS: Retrospective assessment of 546 all-ceramic anterior and posterior crowns in a general practice. $J$ Prosthet Dent 2000;85:544-50.

5. Erpenstein H, Borchard R, Kerschbaum T: Long-term clinical results of galvano-ceramic and glass-ceramic individual crowns. J Prosthet Dent 2000;83:530-4

6. American National Standard/ American Dental Association: Report on base metal alloys for crown and bridge applications: benefits and risks. Council of Dental Materials, Instruments, and Equipment. J Am Dent Assoc 1985; 111:479-83.

7. Drummond JL, King TJ, Bapna MS, Koperski RD: Mechanical property evaluation of pressable restorative ceramics. Dent Mater 2000;16:226-33.

8. Kelly JR, Benetti P. Ceramic materials in dentistry: Historical evolution and current practice. Australian Dental Journal.2011;56:84-96.

9. Conrad HJ, Seong WL, Pesun IJ. Current ceramic materials and systems with clinical recommendations: a systematic review. J Prosthet Dent. 2007;98:389-404.

10. Giordano R, McLaren EA. Ceramics overview: classification by microstructure and processing methods. Compend Contin Educ Dent.2010;31:682-4.

11. Fasbinder DJ, Dennison JB, Heys D, Neiva G. A clinical evaluation of chairside lithium disilicate CAD/CAM crowns: a two-year report. J Am Dent Assoc. 2010; 141: $10 \mathrm{~S}-14 \mathrm{~S}$
12. Balkaya MC, Cinar A, Pamuk S. Influence of firing cycles on the margin distortion of three all-ceramic crown systems. J Prosthet Dent. 2005;93:346-55.

13. Contrepois M, Soenen A, Bartala M, Laviole O. Marginal adaptation of ceramic crowns: A systematic review J Prosthet Dent. 2013;110:447-54.

14. Quintas AF, Oliveira F, Bottino MA. Vertical marginal discrepancy of ceramic copings with different ceramic materials,finish lines, and luting agents: An in vitro evaluation . J Prosthet Dent. 2004;92:250-7.

15. Borges GA, Faria JS, Agarwal P, Spohr AM, Correr, Sobrinho L, Miranzi BA. In vitro marginal fit of three all ceramic crown systems before and after cementation. Oper Dent. 2012;37:641-9.

16. Al-Dwairi ZN, Alkhatatbeh RM, Baba NZ, Goodacre CJ A comparison of the marginal and internal fit of porcelain laminate veneers fabricated by pressing and CAD-CAM milling and cemented with 2 different resin cements. J Prosthet Dent. 2019;121:470-6.

17. Basheer RR, Elsayed SM, Bahgat SF. Assessment of accuracy of different CAD/CAM fabricated porcelain laminate veneers. Egyptian Dental Journal. 2017; 63:1841-55.

18. Rashad TM, Abdou AM. Fracture resistance of three different all-ceramic crown systems. Egy Dent J.2001; 47: 933.

19. Guazzato, M., Albakry M., Simon P. Ringer, S. P., and Michael V. Swain, M. V.: Strength, fracture toughness and microstructure of a selection of all-ceramic materials. Part II. Zirconia-based dental ceramics. Dent. Mater. 2004; 20: 449-56.

20. Fleming G J P., Nolan L., and Harris J. The in-vitro clinical failure of all-ceramic crowns and the connector area of fixed partial dentures: the influence of interfacial surface roughness. J. Dent.2005;33:405-12.

21. Papadiochou S, Pissiotis AL. Marginal adaptation and CAD-CAM technology: A systematic review of restorative material and fabrication techniques. J Prosthet Dent. 2017.

22. Majeed MA, Al-Adel SK. Evaluation of the marginal and internal fitness of full contour CAD/CAM crowns made from zirconia, lithium disilicate, zirconia-reinforced lithium silicate and hybrid dental ceramic by silicone replica technique (A comparative In vitro study). Journal of Genetic and environmental resources conservation. 2016; 4:10-20. 